\title{
Peptides and the Control of Meal Size
}

\author{
S. C. Woods, D. B. West, Leslie J. Stein, L. D. McKay, Elizabeth C. Lotter, Stephanie G. Porte, \\ Nancy J. Kenney, and D. Porte, Jr. \\ Departments of Psychology and of Medicine, The Diabetes Research Center, and The Regional Primate Research Center, \\ University of Washington, and The Seattle Veterans Administration Hospital, Seattle, Washington, USA
}

Summary. There are now a large number of experiments demonstrating that peripheral administration of exogenous cholecystokinin or its synthetic analogue, CCK-8, reduces meal size in a number of species. The peptide interacts with other factors which influence satiety, and treatments thought to be effective in eliciting secretion of cholecystokinin have predictable effects on meal size. Cholecystokinin is effective in the genetically obese Zucker rat, obese rats with lesions of the ventromedial hypothalamus, and subdiaphragmatically vagotomized rats. Somatostatin and bombesin are also reasonable candidates for satiety factors. Intraperitoneal naloxone reduces meal size in rats, and beta-endorphin injected intraventricularly causes an increase in meal size of $50 \%$ over 30 minutes. We conclude that cholecystokinin and bombesin may interact in weight regulation and control of meal time food intake.

Key words: Satiety, CCK, bombesin, somatostatin, beta-endorphin, VIP, meal size, vagotomy, Zucker (Fatty) rats

We have presented the view [1] that factors which regulate food intake can be separated into two categories, namely those that vary with the adipose mass and which, therefore, carry information regarding the level of adiposity, and those that affect food intake independently of body weight. We reviewed our hypothesis that the amount of insulin acting at the brain, perhaps via the cerebrospinal fluid (CSF), is a key factor in the adiposity-determined regulation of food intake over long intervals. In the present paper, we shall review the evidence that other gastroenteropancreatic peptide hormones affect the size of individual meals and act relatively independently of the size of the adipose mass. In particular, we shall consider certain peptide hormones which are normally secreted in response to ingested foodstuffs. Some of these peptides act to reduce meal size and others act to increase it.

This paper is divided into four sections. The first reviews selectively the literature dealing with peptides and satiety, focusing upon the ability of cholecystokinin-pancreozymin (CCK) to reduce meal size. The second section covers other peptides purported to reduce meal size, and focuses upon recent work in our own lab utilizing the hormones somatostatin (SRIF) and bombesin (BB). A third section deals with the possibility that some other peptides, perhaps the endorphins, function as appetite enhancers, thus countering these other peptides. The final section examines some possible interactions of the peptide and meal size system with the insulin body adiposity system discussed in the previous paper [1].

\section{CCK and Satiety}

Because of the clinical importance attached to the determination of factors which might regulate appetite and/or the consumption of food, considerable research has been directed to this end. However, until the past fifteen years most of the focus was on psychological factors and nutrients, especially glucose levels $[2,3]$, as major controllers. Although a large number of experiments provided evidence that nutritional deficit or excess might have an influence on meal size, no unified approach or conclusion was evident (see $[4,5]$ for reviews).

Davis and his colleagues were among the first to suggest that non-nutrient circulating factors associ- 
ated with normal meals might influence meal size. In those experiments [6], rats were fed a normal meal and were than cross-perfused with another rat such that the blood of the two was intermixed. The second rat was unfed. After the cross-perfusion, it was found that the unfed rat ate a considerably smaller meal than it normally ate. Since the same rats were not adversely affected by being cross-perfused when both were hungry, Davis and his colleagues reached the conclusion that some compound carried in the blood had the ability to limit the amount eaten [6]. Such a compound has come to be called a "satiety factor".

Since a number of hormones are secreted by the gut when an animal begins eating, and since the years of searching for a blood-borne nutrient which might reliably reduce meal size had not been particularly fruitful, attention became focused upon the possibility that non-nutrient signals from the gut might be the unknown satiety factor(s). A major change in direction was provided by the finding that rats with open gastric fistulas ate continuously, but could be suppressed by small amounts of intraduodenal food [7]. Based on earlier work suggesting that crude extracts of intestinal mucosa reduced meal size, Gibbs, Smith and their colleagues examined preparations of gut peptides. They were the first to demonstrate unambiguously that purified $\mathrm{CCK}$, as well as the synthetic octapeptide of CCK, CCK-8, would reduce meal size in a dose-dependent manner when injected into mildly hungry rats just prior to a meal $[7,8]$. This area of research has mushroomed since those original reports, and several reviews are now available [9-11]. It is not the intent here to review all of the findings linking CCK to the control of meal size; rather, we shall review some of those aspects of the literature which we feel provide insight into the overall weight-regulatory and energy-balance maintaining system.

Synthetic CCK-8 (and purified natural CCK to a much lesser extent) has been administered in a number of feeding situations (mild food deprivation [7-11], palatability eating [12], feeding associated with water consumption [13], tail-pinch induced eating [14], and sham-eating $[15,16])$, to a number of species (mainly rats and mice, but also monkeys and humans, see [11]), and at a variety of doses (typically from 1 to $10 \mu \mathrm{g} / \mathrm{kg}$ ) with the common finding that subsequent meal size was reduced. Of primary interest, of course, is whether or not endogenous CCK might play a similar role during natural feeding. Although definitive results will have to wait until a reliable and sensitive assay for circulating CCK exists, several experiments are suggestive. In those experiments, rats [17] or monkeys [18] were given foods which are potent releasers of endogenous
CCK, such as 1-phenylalanine and/or egg yolk. The animals were then allowed to feed and ate less than would be expected.

It is suggested that CCK (and other gut hormones) act to terminate the meal (see [11]). To date, there are no published attempts to prolong meals by the administration of CCK antagonists or antibodies, nor are there published attempts to remove the CCK-secreting tissues. In spite of this deficit, the studies published to date collectively make compelling argument that CCK may be a natural satiety factor.

For several years, we have also been investigating the mechanism by which CCK- 8 reduces feeding by rats. We have found that CCK- 8 was equally effective in reducing the meal size of rats with lesions of the ventromedial hypothalamus (VMH) as it was in normal controls [19]. The VMH has often been categorized as a satiety center of the brain, and as such its destruction might have been expected to interact with CCK-elicited meal reduction. In that experiment, as in most of the experiments described below, the hormone (CCK-8 in this instance) was administered intraperitoneally (IP) to mildly (5 to $7 \mathrm{~h}$ ) food-deprived rats just before food was presented. The food presented in that experiment [19] was rat chow pellets, as VMH-lesioned rats are fussy eaters and tend to eat more of some foods than others.

In a later experiment, we gave the rats a more preferred liquid diet and found that at some doses the CCK- 8 would reduce the meal size of control rats but not lesioned rats [20]. This suggests that CCK has the important property of interacting in predictable ways with other factors known to influence meal size, palatability in this instance.

More recently, we have compared the efficacy of CCK- 8 in reducing meal size in other models of obesity. When genetically obese Zucker (Fatty) rats were given CCK over a dose range of 1 to $8 \mu \mathrm{g} / \mathrm{kg}$, meal size was suppressed to the same extent (in terms of percentage reduction from each rat's own baseline) as found in their lean littermate controls. Only at the highest dose $(8 \mu \mathrm{g} / \mathrm{kg}$, IP) was there a suggestion that the Fatties might be slightly less sensitive (a mean reduction of meal size of $75 \%$ for the controls vs. $57 \%$ for the Fatties) to the peptide. The diet in this study was a highly preferred liquid diet (Ensure, Ross Labs), so these findings might reflect a basic difference between the genetically obese and the hypothalamically obese rats. There is one report suggesting that both obese and weight-reduced Fatties are less sensitive to partially purified CCK-33 [21].

We have also examined the efficacy of CCK -8 in vagotomized animals. The picture here is complex 
because there are conflicting reports in the literature. This may be due to a number of methodological problems associated with this type of study (see below). There is one report that subdiaphragmatic vagotomy has no effect on the ability of CCK to reduce feeding [17]. In that paper, completeness of vagotomy was assessed with a test that determined the effectiveness of denervation of the stomach. This is important because another report recently claimed that selective gastric vagotomy significantly reduces the effectiveness of CCK in reducing meal size [22]. Several years ago, we (Kulkosky and Woods, unpublished data) made total subdiaphragmatic vagotomies in a group of rats and observed that the vagotomized rats did not suppress their consumption of a pellet diet when given CCK. Due to the controversy, we have re-examined this issue in more detail. Using the preferred liquid diet for the test meal, we have found that vagotomy shifts the dose-effect curve slightly to the right. CCK-8 was approximately half as effective in the vagotomized as the control rats, a dose $(2 \mu \mathrm{g} /$ $\mathrm{kg}$ ) suppressing the mean intake of the controls by $40 \%$ and suppressing the mean intake of the vagotomized animals by around $20 \%$. Thus, the type of meal may be important to the conclusion.

Another important factor in the study of ingestive behavior by vagotomized rats is the degree of discomfort caused by the food. In an attempt to reduce gastric stasis, we routinely perform a pyloroplasty along with the vagotomy (see [23]). Additionally, in the above study the rats were given a liquid diet to prevent gastric obstruction. With these treatments, CCK-8 was effective in reducing meal size as stated above. A second important consideration may be the baseline intake. Our vagotomized rats (even with the pyloroplasty and the liquid diet) averaged only around $5 \mathrm{ml}$ consumption over the 30 -min test during their baseline control days even though total daily calories were similar to controls. This is compared to an average consumption of around $25 \mathrm{ml}$ by the controls. Decreases from such a low baseline are difficult to measure and hard to interpret. Certainly comparisons of absolute decrements of food intake between groups are meaningless; but calculations of percent changes are subject to considerable error. It may be that with such a low baseline, the interpretation of CCK's effectiveness in vagotomized rats will always be ambiguous. This is especially true if it is true that CCK can terminate eating only after it has begun, rather than preventing it all together [24]. As long as the animal must initiate the meal, suppression will remain difficult to measure when the baseline consumption is very low.

One problem common to the investigation of all putative satiety factors is the possibility that illness may account for the suppression of food intake but be misinterpreted as satiety. This is an issue which continues to be debated hotly in the literature and there is no easy solution to it. One approach has been to associate the administration of a putative satiety factor with the consumption of a novel flavour. Considerable evidence suggests that nauseating or toxic drugs, when administered in this manner, cause aversion to a flavour such that the animal will avoid consuming that flavour in the future [25]. When CCK has been associated with the consumption of a novel flavour, the results have been equivocal. In some experiments, no aversion was observed $[7,19,26]$, while in others, CCK caused the formation of a taste aversion $[27,28]$. However, the sensitivity of this technique is such that under some conditions even the infusion of a small amount of physiological saline can cause the formation of a significant aversion [25].

Because of the problems associated with interpreting taste aversions, other controls have been employed. Gibbs and Smith and their colleagues have adopted the strategy of assessing the "complete behavioural sequence of satiety". The rationale is that when a rat normally eats to satiety, it thereafter engages in a number of predictable, almost stereotyped behavioural patterns including grooming and drowsiness. They argue that since CCK elicits a reduction of food intake which is followed by an apparently identical sequence of behaviour patterns [29], the cessation of eating must be natural. Another approach has been to see if behaviour patterns other than eating are affected by the drug. CCK has been reported not to influence water intake in some experiments $[19,30]$ but to reduce it in others [31]. A final strategy is to administer other peptides of comparable molecular weight. If these have no effect on food intake whereas a specific experimental peptide does, it strengthens the argument for a specificity of effect. We employed this strategy in our evaluation of insulin as a longterm weight-regulating peptide in baboons [32].

No matter what strategy or control condition is employed, there are always valid criticisms [28, 33]. One can never get around the argument that giving a synthetic peptide via an injection into the peritoneal cavity is unnatural. On the other hand, the counter argument that these peptides are all secreted into the blood normally when we eat, and that natural satiety, if food intake is excessive, might itself create a degree of illness, is equally compelling. As stated above, experiments are needed in which endogenous CCK and other peptides are prevented from acting either through use of specific antagonists or by removal of the source. Such experiments would go a long way toward resolving the illness issue. 
Table 1. Partial list of peptides reported to reduce food intake in one or more species. The peptides listed in the lower section are reported to have no effect

\begin{tabular}{ll}
\hline Peptide & Reference(s) \\
\hline Cholecystokinin-pancreozymin & $\begin{array}{l}7,8,9,10,11 \\
\text { (and many others) }\end{array}$ \\
Bombesin & $37,43,63,78$ \\
Somatostatin & $35,36,66,67$ \\
Thyrotrophin releasing hormone & 65 \\
Pancreatic polypeptide & 66,67 \\
Glucagon & 68 \\
Insulin & $32,69,70$ \\
Calcitonin & 71 \\
Caerulein & $72,73,74$ \\
Enterogastrone & 75 \\
Anorexigenic tripeptide & 76 (but see 77$)$ \\
\hline Luteinizing hormone releasing hormone & 65,66 \\
Pentagastrin & 66 \\
Gastrin & 16 \\
Secretin & 16 \\
Gastric inhibitory peptide & 16 \\
\hline
\end{tabular}

Table 2. CNS effects of meal related peptides. Peptides were administered intraventricularly to rats in a total injection volume of $1 \mu \mathrm{l}$. Intake of a liquid diet (sweetened, condensed milk) was determined over a $30 \mathrm{~min}$ interval immediately following injection and compared to that on a control day

\begin{tabular}{lrl}
\hline Peptide & Dose & Effect \\
\hline Cholecystokinin & $100 \mathrm{ng}$ & None \\
Gastric inhibitory peptide & $100 \mathrm{ng}$ & None \\
Beta-endorphin & $20 \mathrm{ng}$ & None \\
& $100 \mathrm{ng}$ & None \\
& $200 \mathrm{ng}$ & Increase \\
& $1 \mu \mathrm{\mu g}$ & None \\
Met-enkephalin & $1 \mathrm{ng}$ & None \\
& $10 \mathrm{ng}$ & None \\
& $100 \mathrm{ng}$ & None \\
Met-enkephalin analogue & $2 \mathrm{ng}$ & None \\
(D-Ala ${ }_{2}$-N-Me ${ }_{5}$-Met-enkephalin amide) & $1 \mu \mathrm{\mu g}$ & None \\
Neurotensin & $100 \mathrm{ng}$ & None \\
Pancreatic polypepide (Porcine) & $10 \mathrm{ng}$ & None \\
Vasoactive intestinal peptide & $10 \mathrm{ng}$ & Decrease \\
& $100 \mathrm{ng}$ & None \\
& $1 \mu \mathrm{ng}$ & None \\
Substance P & $10 \mathrm{ng}$ & None \\
& $200 \mathrm{ng}$ & None \\
\hline
\end{tabular}

\section{Other Putative Satiety Peptides}

Although CCK has been the most studied of the putative satiety hormones, a number of others have been investigated for this property. Table 1 provides a list of many of these peptides along with appropriate citations. As can be seen, there are so many peptides purported to be satiety factors that it is imperative to employ both common sense and appropriate controls for illness or other non-specific effects in these investigations. Any experiment in which a particular hormone causes an animal to eat less, without appropriate controls, should not be considered evidence for the demonstration of a natural satiety system.

We have been studying a number of peptides other than CCK. One of the first which we investigated was somatostatin (SRIF). Like CCK, SRIF is found both within the central nervous system (CNS) and in the gut. It is released when animals eat, and is known to influence a number of digestive processes [34]. We initially administered SRIF IP to rats using a design comparable to that described above. SRIF caused a dose-dependent suppression of meal size over a range from 10 to $1000 \mathrm{ng} / \mathrm{kg}[35,36]$. We also found that intracerebroventricular (IVT) administration had no apparent effect on meal size. Despite the IP suppression of food intake, IP SRIF did not decrease water intake and did not cause the formation of a conditioned taste aversion (at least at the doses which suppressed meal size) [36].

In the baboon, IP administration of SRIF $(1 \mu \mathrm{g} /$ $\mathrm{kg}$ ) also caused a significant reduction of meal size while IVT administration had no effect [36]. We concluded that a role in satiety would fit in well with the known physiology of SRIF, and that it therefore should be considered as a possible peripheral satiety factor.

Gibbs and his colleagues recently reported that the peptide bombesin (BB) reduces meal size in rats [37]. BB was originally isolated from frog skin [38] and BB-like peptides have been found in mammalian tissues including the CNS and the gut $[39,40]$. There is evidence that a specific mammalian peptide, called gastrin releasing peptide (GRP), may actually be mammalian BB [41]. The synthetic amphibian peptide (BB-14) has many influences on regulatory behavior including effects on body temperature and blood glucose [42].

In our hands, BB-14 causes a reduction of meal size at doses similar to CCK and SRIF. Unlike CCK and SRIF, it acts both when administered peripherally (IP or SC) or centrally (IVT). We have also found that $\mathrm{BB}$ is effective in obese VMH-lesioned rats [43].

In order to control or test for illness, we have given $\mathrm{BB}$ in the standard conditioned taste aversion paradigm. In that experiment, a dose of BB was first determined which would lower $30 \mathrm{~min}$ food intake by $50 \%$. A dose of lithium chloride was chosen which, when given prior to eating, reportedly lowered food intake by $25 \%$ [33]. Lithium is a known toxic agent which reliably causes the formation of conditioned taste aversions [25]. When these two drugs were then individually associated with consumption of a novel 
flavour, an aversion formed to the flavour only in the lithium-treated rats and not in the BB-treated rats. To control for non-specific effects of $\mathrm{BB}$ when given centrally, we have given other peptides IVT which had no apparent effect on meal size over a comparable dose range. Therefore, $\mathrm{BB}$ may also be a satiety hormone. Table 2 lists many of the peptides we have administered IVT and the doses used. In all of these experiments, the rats were initially fitted with standard IVT cannulas [44] which were verified for patency both prior to and following the peptide tests with injections of $1 \mu \mathrm{l}$ of saline containing $500 \mathrm{ng}$ of carbachol. Rats had to consume at least $3 \mathrm{ml}$ of water within $5 \mathrm{~min}$ following the administration of carbachol to be included in the analyses.

Although in general, our results agree well with those of Gibbs and his colleagues concerning the effect of BB on food intake, there is one important difference. In their paper [37], they reported that the larger the dose of $\mathrm{BB}$, the greater the reduction of food intake. Our data (which are still being collected) suggest that a maximum suppression of between 40 and $50 \%$ occurs when $\mathrm{BB}$ is injected peripherally. This degree of suppression occurs when $4 \mu \mathrm{g} / \mathrm{kg}$ of $\mathrm{BB}-14$ is given IP. There is no difference when the dose is raised to 8,16 or even $32 \mu \mathrm{g} / \mathrm{kg}$. We have comparable findings when the $\mathrm{BB}$ is given $\mathrm{SC}$.

In one experiment, we have explored the interaction of submaximal doses of BB and CCK. Although these experiments are still in progress, the data suggest that the two are additive. For example, a dose of CCK $(0.25 \mu \mathrm{g} / \mathrm{kg})$ which causes a $15 \%$ suppression of meal size when combined with a dose of $\mathrm{BB}$ $(0.25 \mu \mathrm{g} / \mathrm{kg})$ which causes a $9 \%$ suppression alone, resulted in a combined suppression of $27 \%$. This apparent additivity remains linear until the combined effect is $80 \%$ suppression, which is greater than the maximal effect of either peptide given alone.

In summary, at present three peptides, CCK, SRIF and $\mathrm{BB}$, are reasonable candidates for satiety factors. It is noteworthy that a large number of other peptides, at comparable doses, have no such effect (Table 2). In our hands, the only other peptide which reduced food intake reliably was vasoactive intestinal polypeptide (VIP) when given IVT. At a dose of $10 \mathrm{ng}$, it caused a reduction of meal size of $25 \%$. We have not tested it peripherally, nor have we given it in a conditioned taste aversion paradigm.

\section{Appetite Enhancing Peptides}

The hypothesis that peptides normally serve to regulate meal size suggests that some peptides might increase food intake. Over the past 15 years, there have been suggestions that the opiate antagonist, naloxone, when given to hungry rats, caused a reduction of meal size [45-47]. We find that naloxone $(0.5 \mathrm{mg} / \mathrm{kg}$ IP $)$ reduces meal size by $22 \%$ in rats and that $1 \mathrm{mg} / \mathrm{kg}$ reduces meal size by $33 \%$. However, the observation that naloxone also reduces water intake $[48,49]$ suggested a non-specific action.

Interest was sparked when Margules and his colleagues reported that naloxone reduces food intake more effectively in genetically obese mice and rats [50]. In that paper, it was reported that these obese animals have elevated levels of beta-endorphin within the pituitary and that the increase of pituitary beta-endorphin parallels the development of obesity [50]. To date, there are two reports that the central administration of beta-endorphin increased eating by rats. In one report, the drug was injected directly into the ventral hypothalamus [51]. We found [52] that the IVT administration of $200 \mathrm{ng}$ of beta-endorphin caused an increase of meal size of $50 \%$ over $30 \mathrm{~min}$. However, smaller doses ( 1 to $100 \mathrm{ng}$ ) were not effective and larger doses ( $500 \mathrm{ng}$ to $5 \mu \mathrm{g}$ ) caused a slight decrease of eating. At none of these doses did we observe the apparent catatonia reported by Bloom and his colleagues [53]. Because of the narrowness of the range of effectiveness, we repeated the basic study on four groups of rats run over a several-month period. In every instance, the dose of $200 \mathrm{ng}$ caused a comparable increment of eating, therefore we feel confident that the effect is genuine.

In an initial attempt to determine the mechanism through which beta-endorphin works, we gave comparable doses of met-enkephalin (Table 2), as well as a longer-acting analogue of met-enkephalin, into the cerebrospinal fluid (CSF), but observed no effect on food intake at the doses employed. The recent description of two types of opiate receptors [54] may explain the rather curious dose-effect curve of beta endorphin and the lack of effect of met-enkephalin.

It should be clear that the interpretation of increments of food intake is somewhat less ambiguous than that of decrements, because it is unlikely that illness would cause animals to eat more. A potential problem would be that beta-endorphin, at the dose which increases food intake, acts as a general stimulant of all behaviour patterns. This seems unlikely because $200 \mathrm{ng}$ of beta-endorphin given IVT had no effect on water intake in our hands.

\section{Possible Interactions of the Weight-Regulator and Satiety Systems}

As discussed elsewhere [1], we are postulating that satiety is determined by factors sensitive to the size of fat stores interacting with factors sensitive to food ingestion (Fig. 1). 


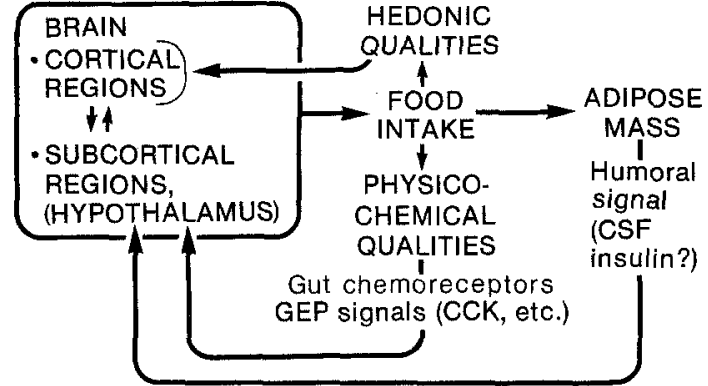

Fig. 1. Schematic diagram depicting some of the influences of a meal and its accompanying stimuli upon food-intake controlling areas of the CNS

Recent research suggests the type of neuro-physiological interaction that may occur. Oomura found neurons in the hypothalamus which respond to insulin when it is applied iontophoretically, and called them "glucose-sensitive insulin-receptor neurons" $[55,56]$. Recently, others have been applying other peptides to these cells once they have been identified as insulin responsive. They have found that the application of $\mathrm{BB}$ enhances the response to insulin [57]. In that experiment, the administration of $\mathrm{BB}$ alone had no effect on the electrical activity of the neurons, whereas the combination of BB plus insulin caused a greater response than insulin alone. This might be expected from the observations that both insulin and $\mathrm{BB}$, when given into the brain, reduce food intake (see above). CCK, when administered in the same manner, did not influence these neurons, but did alter electrical activity of some cortical neurons [58]. The suggestion is that the regulation of food intake by CCK and BB is quite different even though both have the ability to reduce food intake. Consistent with this concept, Smith and his colleagues find CCK not to be effective when given to animals with selective gastric vagotomy (22, but see the discussion above) whereas the efficacy of $\mathrm{BB}$ is unaltered by vagotomy (J. Gibbs, personal communication).

In our hands, BB effectively reduces meal size when given IVT whereas CCK has no such effect (Table 2). The evidence therefore suggests that CCK and $\mathrm{BB}$ act at different sites and in different ways in rats. At present, it seems reasonable to hypothesize that $\mathrm{BB}$ interacts centrally by interacting with the insulin-sensitive weight-regulatory system whereas CCK acts elsewhere and interacts with other (shortterm), nutritionally-releated signals.

Any weight regulatory system, if it is to remain efficacious over long intervals, should not change its properties as weight fluctuates. If an animal gains or loses weight, the system should not adapt to the new level. Rather, it should continue to recognize the discrepancy and trigger restorative measures whenever possible. All evidence on the regulation of body adiposity suggests that this is the case $[59,60]$ and it is not surprising that changes of plasma insulin in association with changes of body weight or diabetes did not lead to a change of CNS insulin receptors [61, 62].

We have been studying the effects of repetitive administration of $\mathrm{BB}$. When rats are forced to eat three meals ( 30 min each) a day, and given BB just prior to each meal, they lose weight and the $B B$ remains as effective over several days as it was on initial administration. There is no apparent change of efficacy as weight is lost ([63] and see [43]). On the other hand there is a report that when CCK is repeatedly administered to rats, its effectiveness decreases over time [64]. In that experiment, the initial administration of the CCK caused the expected reduction of meal size; however, as the animals ate less and began losing weight, the ability of CCK to cause a comparable suppression of food intake grew smaller and smaller. It is as if an undernourished rat required more CCK for the same degree of suppression. These studies confirm that $\mathrm{CCK}$ and $\mathrm{BB}$ do not act in the same way. We suggest that BB acts at the non-adapting weight-regulatory system in which insulin is a major controller, and that CCK functions as part of some other peripheral system responsive to meal feeding.

Acknowledgements. Research reported in this review was partially supported by National Institutes of Health Research Grants Nos. AM-17844 and AM-12829, and also by the Physiology/Psychology Training Grant (GM-07108), the University of Washington Diabetes Research Center (AM-17047), the Veterans Administration and the Northwest Regional Primate Research Center (RR-00166). We thank R. Guillemin of the Salk Institute for the somatostatin, J. Rivier of the Salk Institute for the bombesin-14, and S. J. Lucania at Squibb Laboratories for the cholecystokinin-8 (SQ 19, 844).

\section{References}

1. Porte D Jr, Woods SC (1981) Insulin and the regulation of body weight. Diabetologia 20: 274-280

2. Mayer J (1955) Regulation of energy input and body weight. The glucostatic theory and the lipostatic hypothesis. Ann NY Acad Sci 63: 15-43

3. Mayer J (1952) The glucostatic theory of regulation of food intake and the problem of obesity. Bull NE Med Cen 14: 43-49

4. Epstein AN, Nicolaidis S, Miselis R (1975) In: Mogenson GJ, Calerasu FR (eds) Neural integration of physiological mechanisms and behavior. University of Toronto Press, Toronto, p 148-168

5. Hoebel BG (1971) Regulation of food intake. Annu Rev Physiol 33: 533-558

6. Davis JD, Gallagher RJ, Ladove RF, Turansky AJ (1969) Inhibition of food intake by a humoral factor. J Comp Physiol Psychol 67: 407-417

7. Smith GP, Gibbs J, Young RC (1974) Cholecystokinin and intestinal satiety in the rat. Fed Proc 33: 1146-1149 
8. Gibbs J, Young RC, Smith GP (1973) Cholecystokinin decreases food intake in rats. $\mathbf{J}$ Comp Physiol Psychol 84: 488-495

9. Mueller K, Hsaio S (1978) Current status of cholecystokinin as a short term satiety hormone. Neurosci Behav Rev 2: 79-87

10. Smith GP (1976) Humoral hypotheses for the control of food intake. In: Bray G (ed) Obesity in perspective, vol 2, part 2. National Institutes of Health, Bethesda, p 349-355

11. Smith GP, Gibbs J (1979) Postprandial satiety. Prog Psychobiol Physiol Psychol 8: 179-242

12. Edwards G, Ritter RC (1979) Area postrema lesions cause increased intake of highly palatable food. Soc Neurosci Abstr 5: 215

13. Kulkosky PJ (1980) Reduction of drinking-associated feeding by C-terminal octapeptide of cholecystokinin-pancreozymin. Behav Neural Biol 29: 111-116

14. Nemeroff CB, Osbahr AJ III, Bissette G, Jahnke G, Lipton MA, Prange AJ Jr (1978) Cholecystokinin inhibits tailpinched induced eating in rats. Science 200: 793-794

15. Gibbs J, Young RC, Smith GP (1973) Cholecystokinin elicits satiety in rats with open gastric fistulas. Nature 245: 323-325

16. Lorenz DN, Kreielsheimer G, Smith GP (1979) Effect of cholecystokinin, gastrin, secretin and GIP on sham feeding in the rat. Physiol Behav 23: 1065-1072

17. Anika SM, Houpt TR, Houpt KA (1977) Satiety elicited by cholecystokinin in intact and vagotomized rats. Physiol Behav 19: 761-766

18. Gibbs J, Falasco JD, McHugh PR (1976) Cholecystokinindecreased food intake in rhesus monkeys. Am J Physiol 230: $15-18$

19. Kulkosky PJ, Breckenridge C, Krinsky R, Woods SC (1976) Satiety elicited by the $C$-terminal octatpeptide of cholecystokinin-pancreozymin in normal and VMH-lesioned rats. Behav Biol 18: 227-234

20. Krinsky R, Lotter EC, Woods SC (1979) Appetite suppression caused by $\mathrm{CCK}$ is diet specific in VMH-lesioned rats. Physiol Psychol 7: 67-69

21. McLaughlin CL, Baile CA (1978) Cholecystokinin, amphetamine and diazepam and feeding in lean and obese Zucker rats. Pharmacol Biochem Behav 10: 87-93

22. Smith GP, Jerome C, Eterno R, Cushin B (1979) Selective gastric vagotomy decreases the satiety effect of cholecystokinin in rats. Soc Neurosci Abstr 5: 224

23. Woods SC, Bernstein IL (1980) Cephalic insulin response as a test for completeness of vagotomy to the pancreas. Physiol Behav 24: 485-488

24. Mueller K, Hsiao S (1980) Oral preloads of liquid diet and hormonal satiety mechanisms. Physiol Behav 24: 667-673

25. Revusky SH, Garcia J (1970) Learned associations over long delays. In: Bower G, Spence JT (eds) The psychology of learning and motivation: Advances in research and theory. Academic Press, New York, p 1-74

26. Holt J, Antin J, Gibbs J, Young RC, Smith GP (1974) Cholecystokinin does not produce bait-shyness in rats. Physiol Behav 12: 497-498

27. Kraly FS, Carty WJ, Resnick S, Smith GP (1978) Effect of cholecystokinin on meal size and intermeal interval in the sham feeding rat. J Comp Physiol Psychol 92: 697-707

28. Deutsch JA, Hardy WT (1977) Cholecystokinin produces bait-shyness in rats. Nature 266: 196

29. Antin J, Gibbs J, Holt J, Young RC, Smith GP (1975) Cholecystokinin elicits the complete behavioral sequence of satiety in rats. $J$ Comp Physiol Psychol 89: 784-790

30. Bernstein IL, Lotter EC, Zimmerman JC (1976) Cholecystokinin-induced satiety in weanling rats. Physiol Behav 17: $541-543$

31. Koopmans HS, Deutsch JA, Branson PJ (1972) The effect of cholecystokinin-pancreozymin on hunger and thirst in mice. Behav Biol 7: 441-444
32. Woods SC, Lotter EC, McKay LD, Porte D Jr (1979) Chronic intracerebroventricular infusion of insulin reduces food intake and body weight of baboons. Nature 282: 503-505

33. Deutsch JA, Gonzalez MF (1978) Food intake reduction: Satiation or aversion? Behav Biol 24: 317-326

34. Guillemin R, Gerich JE (1976) Somatostatin: Fhysiological and clinical significance. Annu Rev Med 27: 379-388

35. Lotter EC, Woods SC, Porte D Jr (1979) Somatostatin decreases food intake of baboons. Diabetes 26:358

36. Lotter EC, Krinsky R, McKay JM, Treneer CM, Porte D Jr, Woods SC (in press) Somatostatin decreases food intake of rats and baboons. J Comp Physiol Psychol

37. Gibbs J, Fauser DJ, Rowe EA, Rolls BJ, Rolls ET, Maddison SP (1979) Bombesin suppresses feeding in rats. Nature 282: 208-210

38. Erspamer V, Melchiorri P (1975) Actions of bombesin on secretions and motility of the gastrointestinal tract. In: Thompson JC (ed) Gastrointestinal hormones. University of Texas Press, Austin, p 575

39. Moody TW, Pert CB (1979) Bombesin-like peptides in rat brain: Quantitation and biochemical characterization. Biochem Biophys Res Commun 90: 7-14

40. Walsh JH, Holmquist AL (1976) Radioimmunoassay of bombesin peptides: Identification of bombesin-like immunoactivity in vertebrate gut extracts. Gastroenterology 70:948

41. Brown M, Marki M, Rivier J (1980) Is gastrin releasing peptide mammalian bombesin? Life Sci 27: 125-128

42. Brown M (1981) Neuropeptides: Central nervous system effects on nutrient metabolism. Diabetologia [Suppl] 20:

43. Woods SC, McKay LD, Stein LJ, West DB, Lotter EC, Porte D Jr (1980) Neuroendocrine regulation of food intake and body weight. Brain Res Bull 5: 1-5

44. Kenney NJ, Epstein AN (1978) Antidipsogenic role of the Eprostaglandins. J Comp Physiol Psychol 92: 204-219

45. Holtzman SG (1974) Behavioral effects of separate and combined administration of naloxone and d-amphetamine. J Pharmacol Exp Ther 189: 51-60

46. King BM, Castellanos FX, Kastin AJ, Berzas MC, Mauk MD, Olson GA, Olson RD (1979) Naloxone-induced suppression of food intake in normal and hypothalamic obese rats. Pharmacol Biochem Behav 11: 729-732

47. Brands B, Thornhill JA, Hirst M, Gowdey CW (1979) Suppression of food intake and body weight gain by naloxone in rats. Life Sci 24: 1773-1778

48. Holtzman SG (1975) Effects of narcotic antagonists on fluid intake in the rat. Life Sci 16: 1465-1470

49. Stapleton JM, Ostrowski NL, Merriman VJ, Lind MD, Reid LD (1979) Naloxone reduces fluid consumption in water-deprived and non-deprived rats. Bull Psychonom Soc 13: 237--239

50. Margules DL, Moisset B, Lewis MJ, Shibuya H, Pert CB (1978) Beta-endorphin is associated with overeating in genetically obese mice (ob/ob) and rats (fa/fa). Science 202: 988-991

51. Grandison L, Guidotti A (1977) Stimulation of food intake by muscimol and beta endorphin. Neuropharmacology 16: 533-536

52. Kenney NJ, McKay LD, Woods SC, Williams RH (1978) Effects of intraventricular beta-endorphin on food intake in rats. Soc Neurosci Abstr 4: 176

53. Bloom F, Segal D, Ling N, Guillemin R (1976) Endorphins: Profound behavioral effects in rats suggest new etiological factors in mental illness. Science 194: 630-632

54. Smith JR, Simon EJ (1980) Selective protection of stereospecific enkephalin and opiate binding against inactivation by N-ethylmaleimide: Evidence for two classes of opiate receptors. Proc Natl Acad Sci USA 77: 281-284

55. Oomura Y (1976) Significance of glucose, insulin and free fatty acid on the hypothalamic feeding and satiety neurons. In: Novin D, Wyrwicka W, Bray GA (eds) Hunger: Basic 
mechanisms and clinical implications. Raven Press, New York, p 145-157

56. Oomura Y, Ono T, Ooyama H, Wayner MJ (1969) Glucose and osmosensitive neurones of the rat hypothalamus. Nature 222: $282-284$

57. Shiraishi T, Inoue A, Yanaihara N (1980) Neurotensin and bombesin effects on LHA-gastrosecretory relations. Brain Res Bull 5: 133-142

58. Oomura $\mathrm{Y}$, Ohta $\mathrm{M}$, Ishibashi $\mathrm{S}$, Kita $\mathrm{H}$, Okajima $\mathrm{T}$, Ono $\mathrm{T}$ (1978) Activity of chemosensitive neurons related to the neurophysiological mechanisms of feeding. In: Bray GA (ed) Recent advances in obesity research, II. Newman Publishing, London, p 17-26

59. Bray GA (1976) The obese patient. Saunders, Philadelphia

60. Woods SC, Decke E, Vasselli JR (1974) Metabolic hormones and regulation of body weight. Psychol Rev 81: 26-43

61. Havrankova J, Roth J, Brownstein M (1979) Concentrations of insulin and of insulin receptors in the brain are independent of peripheral insulin levels: Studies of obese and streptozotocin-treated rodents. J Clin Invest 64: 636-642

62. Havrankova J, Brownstein M, Roth J (1981) Insulin and insulin receptors in rodent brain. Diabetologia [Suppl] 20: 268-273

63. West DB, Williams RH, Woods SC (Unpublished manuscript) Bombesin reduces food intake and body weight of rats.

64. Mineka S, Snowdon CT (1978) Inconsistency and possible habituation of CCK-induced satiety. Physiol Behav 21: 65-72

65. Vijayan E, McCann SM (1977) Suppression of feeding and drinking activity in rats following intraventricular injection of thyrotropin releasing hormone (TRH). Endocrinology 100: $1727-1730$

66. Malaisse-Lagae F, Carpentier JL, Patel YC, Malaisse WJ, Orci L (1977) Pancreatic polypeptide: A possible role in the regulation of food intake in the mouse. Experientia 33: 915-918

67. Gates RJ, Lazarus NR (1977) The ability of pancreatic polypeptides (APP and BPP) to return to normal the hyperglycaemia, hyperinsulinaemia and weight gain of New Zealand obese mice. Horm Res 8: 189-202
68. Martin JR, Novin D (1977) Decreased feeding in rats following hepatic-portal infusion of glucagon. Physiol Behav 19; $461-466$

69. Nicolaidis S, Rowland N (1976) Metering of intravenous versus oral nutrients and regulation of energy balance. Am J Physiol 231: 661-668

70. VanderWeele DA, Pi-Sunyer FX, Novin D, Bush MJ (1980) Chronic insulin infusion suppresses food ingestion and body weight gain in rats. Brain Res Bull 5: 7-11

71. Perlow MJ, Freed WJ, Carman JS, Wyatt RJ (1980) Calcitonin reduces feeding in man, monkey and rat. Pharmacol Biochem Behav 12: 609-612

72. Stern JJ, Cudillo CA, Kruper J (1976) Ventromedial hypothalamus and short-term feeding suppression by caerulein in male rats. J Comp Physiol Psychol 90: 484-490

73. Houpt TR, Anika SM, Wolff NC (1978) Satiety effects of cholecystokinin and caerulein in rabbits. Am J Physiol 235: R23-R28

74. Mendel VE, Sturdevant RAL, Elashoff J (1980) The effects of caerulein on food intake in the cat. Physiol Behav 24: 629-631

75. Schally AV, Redding RW, Lucien HW, Mayer J (1967) Enterogastrone inhibits eating by fasted mice. Science 157: 210-211

76. Reichelt KL, Foss J, Tygstad O, Edminson PD, Johansen JH, Boler JB (1978) Humoral control of appetite. II. Purification and characterization of an anorexogenic peptide from human urine. Neuroscience 3: 1207-1211

77. Nance DM, Coy DH, Kastin AJ (1979) Experiments with a reported anorexigenic tripeptide: Pyro-glu-his-gly-OH. Pharmacol Biochem Behav 11: 733-735

78. Martin CF, Gibbs $\mathrm{J}$ (in press) Bombesin elicits satiety in sham feeding rats. Peptides

S. C. Woods

Department of Psychology, NI-25

University of Washington

Seattle, WA 98195

USA

\section{Discussion after 'Woods Presentation'}

Oomura: Glucagon has an effect on electrical activity of hypothalamic neurons; yet you found no effect of glucagon on food intake in the baboon. How do you explain this?

Woods: Actually, it's possible that glucagon may have caused a small increase of food intake at the dose we were infusing into the CSF. The number of animals in the experiment was very small.

Bray: How do you think that glycerol might interact with the peptide-controlled satiety system you have described?

Woods: We have not really integrated glycerol into our model. I am aware that several labs are actively pursuing it as a possible factor that reduces appetite. My own opinion is that possible non-specific effects of glycerol have not been totally ruled out, but perhaps others here have more insights in this area.
Steffens: There is an elevation of plasma glycerol in fasted animals as it is released from adipocytes. Since these animals also have elevated appetites. I cannot unterstand a theory based upon glycerol suppressing appetite.

Nicolaidis: On the other hand, since glycerol is an energy substrate, it might be expected to suppress appetite in some non-specific way.

Woods: Yes, but energy sources per se are not particularly effective at suppressing appetite. When we infused glucose intravenously to our baboons, there was no suppression of food intake for several days, suggesting that any effect is slow to occur.

Nicolaidis: We have made comparable observations with glucose infusions into rats. The problem is that infused glucose requires insulin to become elevated before it can serve as an energy source for the body. Glycerol might be different because it requires no such co-factor. 
Fernstrom: In the study where you administered bombesin prior to each of three meals each day, why not simply give the hormone throughout the day, perhaps as one or two large injections? That way the rats could eat spontaneously and not be necessarily underweight.

Woods: In our hands, the effective time over which injected bombesin acts is very short, perhaps 20 minutes or so. The injections would have to be so large that other effects might predominate. A better solution, and one we are pursuing, would be to have an infusion of bombesin automatically begin each time the animal breaks a circuit to begin eating. With the paradigm you have suggested, the animal could eat less immediately after the injection and compensate later, just prior to the next injection.

Sclafani: Pertinent to your suggestion that hedonic effects of food intake may input to the cortex and that CCK seems to act at a different site than some of the other peptides, it has recently been reported that CCK may actually alter the hedonic properties of food; and Oomura has shown that CCK influences cortical rather than hypothalamic neurons. In the study on CCK and the hedonic properties of food, I believe that the CCK suppressed the immediate licking rate for sucrose solutions and that the sweeter solutions were influenced to a greater degree (Physiol Behav (1980) 25: 25). I notice that you carefully stated that the compounds listed in the top of Table 1 have been reported to reduce feeding, but did not call them "satiety factors". Does this imply that you think some of these compounds are acting non-specifically?

Woods: Yes, I think that's likely.

Oomura: Did you measure insulin levels when you added beta-endorphin to the CSF of your rats?

Woods: No, we only measured food intake.
F. Jeanrenaud: Is there a difference in the basal levels of bombesin between normal and VMH-lesioned animals?

Woods: I don't know; perhaps Dr. Brown can answer that question?

Brown: I don't think that it's been measured.

Berthoud: Is it possible that the hyperglycemia seen by Dr. Brown is causing the suppression of food intake which you have observed?

Woods: It's possible, but I doubt it. The time courses of the two responses are different. Further, we observe the suppression of feeding when the bombesin is given either centrally or peripherally, whereas as I understand it, the hyperglycemia is seen only when the bombesin is given centrally. This last difference could be a dose problem, however.

Steffens: Exactly where in the brain is bombesin found?

Brown: We've done some punch experiments to answer your question, but they haven't been totally satisfactory. In our hands, the anterior hypothalamus seems to have the highest concentrations, and that's about all we can say at this time.

Bray: One of the virtues of insulin as a satiety factor seems to be that it does not clear from the CSF as rapidly as other compounds. How do bombesin and the other putative satiety peptides fare in this regard?

Woods: I do not know bombesin, but in general, most peptides clear fairly slowly from the CSF.

Brown: That's true. I don't believe there are any data specifically on bombesin in this regard. 